\title{
Risk Factors for Eye Disorders Caused by Paclitaxel: A Retrospective Study
}

\author{
Yusuke Noguchi, ${ }^{*}$, Yugo Kawashima, ${ }^{a}$ Megumi Maruyama, ${ }^{a}$ Hiroko Kawara, ${ }^{a}$ Yoko Tokuyama, ${ }^{a}$ \\ Kiyoshi Uchiyama, ${ }^{b}$ and Yoshihiro Shimizu ${ }^{b}$ \\ ${ }^{a}$ Department of Pharmacy, Kyoto Okamoto Memorial Hospital; 58 Nishinokuchi, Sayama, Kumiyama-cho, Kuse-gun, \\ Kyoto 613-0034, Japan: and ${ }^{b}$ Department of Digestive Surgery, Kyoto Okamoto Memorial Hospital; 58 Nishinokuchi, \\ Sayama, Kumiyama-cho, Kuse-gun, Kyoto 613-0034, Japan. \\ Received June 9, 2018; accepted August 3, 2018
}

\begin{abstract}
Paclitaxel and nanoparticle albumin-bound paclitaxel are known to cause adverse events of eye disorders, such as cystoid macular edema. However, at present, the risk factors remain unclear. Therefore, risk factors for eye disorders caused by paclitaxel and nanoparticle albumin-bound paclitaxel were studied. This retrospective study targeted patients who were newly administered paclitaxel or nanoparticle albumin-bound paclitaxel at Kyoto Okamoto Memorial Hospital between April 1, 2012, and March 31, 2017. Eye disorder occurrence was defined as an event in which the pharmacist confirmed the symptoms in a patient interview and the ophthalmologist diagnosed the disorder. To analyze the risk factors, logistic regression analysis using 41 factors was performed. Of 128 subjects, $13(10.2 \%)$ had eye disorders with symptom degrees of Grades 1 and 2. The symptoms were conjunctivitis or subconjunctival hemorrhage (3.1\%), visual acuity reduction $(2.3 \%)$, blurred vision and eye pain (1.6\% each), eye mucus, blepharitis, stye, watering eyes, photopsia, and muscae volitantes $(0.8 \%$ each). In eight patients, the conditions patients improved with spontaneously or with medication use; no improvements were observed the cases of visual acuity reduction, blurred vision, or muscae volitantes. Multivariate logistic regression analysis revealed that a cumulative dose of $\geq 819 \mathrm{mg} / \mathrm{m}^{2}$ (odds ratio: $5.34,95 \%$ confidence interval: $1.32-21.60, p=0.019)$ and baseline alkaline phosphatase $\geq 256 \mathrm{U} / \mathrm{L}$ (odds ratio: $3.74,95 \%$ confidence interval: $1.02-13.70, p=0.046$ ) were significant risk factors associated with eye disorders. In conclusion, it was determined that paclitaxel- and nanoparticle albumin-bound paclitaxelrelated eye disorders might be influenced by cumulative dose and baseline alkaline phosphatase.
\end{abstract}

Key words paclitaxel; nanoparticle albumin-bound paclitaxel; eye disorder; risk factor

In recent years, eye disorders caused by antineoplastic agents have become problematic; for example, tegafur/gimeracil/oteracil (S-1) was reported to induce ocular side effects. ${ }^{1,2)}$ Eye disorders rarely pose a direct fatal risk to life, but it is highly likely that the patient's QOL will be reduced and that their daily activities will be hindered; thus, it is necessary to address the occurrence of these adverse events.

In general, eye disorders are thought to have a low frequency of occurrence relative to adverse events such as bone marrow suppression, nausea, and vomiting. It is therefore probably that eye disorders are missed in daily practice; indeed, they are often discovered following the investigation of a patient's self-reported complaint. Since July 2009 at Kyoto Okamoto Memorial Hospital, pharmacists have been monitoring adverse events for all patients who underwent chemotherapy in the outpatient chemotherapy room $^{3)}$ and we have previously reported that eye disorders were associated with use of paclitaxel $\left.(\mathrm{PTX}),{ }^{4}\right)$ capecitabine, ${ }^{5)}$ oxaliplatin, ${ }^{6}$ docetaxel, ${ }^{7}$ and cabazitaxel. ${ }^{8)}$

PTX and nanoparticle albumin-bound paclitaxel (nab-PTX) are antineoplastic agents used for the treatment of many types of cancer, such as breast cancer, gastric cancer, and lung cancer. Representative adverse events include bone marrow suppression and peripheral neuropathy. Eye disorders, such as macular edema and visual acuity reduction, have also been reported. ${ }^{9-32)}$ It is important to fully recognize risk factors before treatment to allow the early detection of adverse events and thus limit symptom severity. At present, there are many unknown aspects regarding the risk factors for eye disorders caused by PTX and nab-PTX. Therefore, to obtain useful knowledge from routine practice, we have conducted a retrospective study of risk factors concerning eye disorders caused by PTX and nab-PTX.

\section{PATIENTS AND METHODS}

Patients and Study Design Patients who were newly administered PTX or nab-PTX at the Kyoto Okamoto Memorial Hospital between April 1, 2012, and March 31, 2017, were included. Patients were excluded if they had a history of PTX or nab-PTX administration. In addition, patients were excluded if they discontinued PTX or nab-PTX during the study period because of an allergic reaction at initial administration.

This was an observational study that used existing materials that did not contain information that could identify individuals. The ethics committee of Kyoto Okamoto Memorial Hospital approved this study (permission number 2017-03). The requirement for informed consent was waived by the ethics committee owing to the retrospective nature of the study. The study was carried out in accordance with the Ethical Guidelines for Medical and Health Research Involving Human Subjects by the Ministry of Education, Culture, Sports, Science and Technology and the Ministry of Health, Labour and Welfare of Japan.

Data Collection The data were retrospectively collected from electronic medical records. Age, sex, body surface area, 
Eastern Cooperative Oncology Group performance status, ocular disease complications, previous chemotherapy administration, cancer type, total protein, albumin, total bilirubin, aspartate aminotransferase (AST), alanine aminotransferase (ALT), lactate dehydrogenase, alkaline phosphatase (ALP), serum creatinine, white blood cell count, hemoglobin, platelet count, and neutrophil count were investigated at the time of initial administration of PTX or nab-PTX.

The dose and number of administrations of PTX or nabPTX, combination drugs, eye disorders, and peripheral neuropathy were investigated from the initial administration to the final administration. Eye disorders and peripheral neuropathy were graded by using the Common Terminology Criteria for Adverse Events version 4.0 (http://www.jcog.jp/doctor/ tool/CTCAEv4J_20170912_v20_1.pdf).

Definition of Eye Disorders Pharmacists questioned all patients about adverse events for $10-15 \mathrm{~min}$ on the day of administration of PTX or nab-PTX. For typical adverse events, such as nausea and peripheral neuropathy, the presence or absence of the symptoms and the severity of the symptoms were confirmed by closed questions. Other adverse events were confirmed by open questions, such as "Have you experienced a change in physical condition?" As eye disorders are not typical adverse events, they were recorded from a patient's self-reported complaint.

Therefore, in this study, the occurrence of an eye disorder was defined an event in which the pharmacist confirmed the symptoms in a patient interview and the ophthalmologist diagnosed the disorder.

Statistical Analysis To compare categorical data, Fisher's exact probability test was used. For continuous variables, normally distributed values are presented as the mean \pm standard deviation (S.D.). Values that are not normally distributed are presented as the median and range. Student's $t$-test was used to compare normally distributed variables between groups and the Mann-Whitney $U$ test was used to compare non-normally distributed variables between groups.

For the analysis of risk factors, a logistic regression analysis was performed using 41 factors, which comprised patient characteristics, laboratory data, and combination drugs. For the analysis, we converted all continuous variables into two categorical variables, which were set based on the median of the entire population. In the multivariate analysis, to fully account for suppression effects, factors with $p<0.2$ in the univariate analysis were evaluated by using backward stepwise selection.

All statistical analyses were computed by using EZR (Saitama Medical Center, Jichi Medical University, Saitama, Japan, http://www.jichi.ac.jp/saitama-sct/SaitamaHP.files/statmed.html), which is a graphical user interface for $\mathrm{R}$ (The $\mathrm{R}$ Foundation for Statistical Computing, version 3.4.1). More precisely, it is a modified version of $\mathrm{R}$ commander (version 2.4-0) designed to add statistical functions frequently used in biostatistics. $^{33)}$ A $p$-value of $<0.05$ was regarded as statistically significant.

\section{RESULTS}

Patient Characteristics The patient characteristics are shown in Table 1 . Of the 128 subjects, $13(10.2 \%)$ had eye disorders. The cumulative dose $\left(\mathrm{mg} / \mathrm{m}^{2}\right)$ was significantly higher in those who presented with eye disorders than in those who did not (1028.7 vs. 798.2, $p=0.003$, Mann-Whitney $U$ test). The proportion of patients with peripheral neuropathy $\geq$ Grade 2 was significantly higher among those who presented with eye disorders than among those who did not (46.2 vs. $18.3 \%$, $p=0.030$, Fisher's exact probability test). No significant difference was found for any other factor.

Laboratory Data The laboratory data are shown in Table 2. There were no significant differences.

Combinations of Drugs The combinations of drugs used are shown in Table 3. The proportion of patients who used

Table 1. Comparison of Patient Characteristics

\begin{tabular}{|c|c|c|c|c|c|}
\hline & & \multirow{2}{*}{ All patients $(n=128)$} & \multicolumn{2}{|c|}{ Eye disorders } & \multirow{2}{*}{$p$ Value } \\
\hline & & & Yes $(n=13)$ & No $(n=115)$ & \\
\hline Age (years) & median (range) & $65.0(28-87)$ & $66.0(47-82)$ & $65.0(28-87)$ & $0.950^{a)}$ \\
\hline Sex & male/female & $51 / 77$ & $5 / 8$ & $46 / 69$ & $1.000^{b)}$ \\
\hline BSA $\left(\mathrm{m}^{2}\right)$ & mean \pm S.D. & $1.55 \pm 0.14$ & $1.55 \pm 0.10$ & $1.55 \pm 0.15$ & $0.934^{c)}$ \\
\hline ECOG PS & $0 / \geq 1$ & $83 / 45$ & $8 / 5$ & $75 / 40$ & $0.769^{b)}$ \\
\hline Ocular disease complications & yes/no & $20 / 108$ & $2 / 11$ & $18 / 97$ & $1.000^{b)}$ \\
\hline Previous chemotherapy administration & yes/no & $63 / 65$ & $6 / 7$ & $57 / 58$ & $1.000^{b)}$ \\
\hline Paclitaxel & PTX/nab-PTX & $70 / 58$ & $6 / 7$ & $64 / 51$ & $0.566^{b)}$ \\
\hline Dose intensity (mg/m²/week) & mean \pm S.D. & $61.5 \pm 18.2$ & $60.0 \pm 19.3$ & $61.7 \pm 18.1$ & $0.748^{c)}$ \\
\hline Cumulative dose $\left(\mathrm{mg} / \mathrm{m}^{2}\right)$ & median (range) & $819.3(43.3-4461.1)$ & $1028.7(483.3-4461.1)$ & $798.2(43.3-2588.2)$ & $0.003^{a)}$ \\
\hline Peripheral neuropathy & Grade $0-1 / \geq 2$ & $101 / 27$ & $7 / 6$ & $94 / 21$ & $0.030^{b)}$ \\
\hline \multicolumn{6}{|l|}{ Cancer type } \\
\hline Breast & & 56 & 6 & 50 & \\
\hline Gastric & & 25 & 2 & 23 & \\
\hline Lung & & 24 & 2 & 22 & \\
\hline Pancreatic & & 13 & 2 & 11 & \\
\hline Esophageal & & 5 & 1 & 4 & \\
\hline Ovarian & & 4 & 0 & 4 & \\
\hline Cervical & & 1 & 0 & 1 & \\
\hline
\end{tabular}

BSA, body surface area; S.D., standard deviation; ECOG, Eastern Cooperative Oncology Group; PS, performance status; PTX, paclitaxel; nab-PTX, nanoparticle albuminbound paclitaxel. a) Mann-Whitney $U$-test, $b$ ) Fisher's exact probability test, c) Student's $t$-test. 
Table 2. Comparison of Laboratory Data

\begin{tabular}{|c|c|c|c|c|c|}
\hline & & \multirow{2}{*}{ All patients $(n=128)$} & \multicolumn{2}{|c|}{ Eye disorders } & \multirow{2}{*}{$p$ Value } \\
\hline & & & Yes $(n=13)$ & No $(n=115)$ & \\
\hline $\mathrm{TP}(\mathrm{g} / \mathrm{dL})$ & mean \pm S.D. & $6.7 \pm 0.7$ & $6.5 \pm 0.7$ & $6.7 \pm 0.7$ & $\left.0.264^{a}\right)$ \\
\hline Alb (g/dL) & median (range) & $3.8(1.9-4.9)$ & $3.7(3.1-4.5)$ & $3.8(1.9-4.9)$ & $0.749^{b)}$ \\
\hline T-bil (mg/dL) & median (range) & $0.5(0.2-2.9)$ & $0.6(0.2-2.9)$ & $0.5(0.2-2.0)$ & $0.647^{b)}$ \\
\hline $\operatorname{AST}(\mathrm{U} / \mathrm{L})$ & median (range) & $20(11-321)$ & $23(12-139)$ & $20(11-321)$ & $0.520^{b)}$ \\
\hline ALT (U/L) & median (range) & $15(5-276)$ & $18(10-82)$ & $14(5-276)$ & $0.100^{b)}$ \\
\hline $\mathrm{LDH}(\mathrm{U} / \mathrm{L})$ & median (range) & $195(123-7666)$ & $184(124-2000)$ & $196(123-7666)$ & $0.947^{b)}$ \\
\hline $\operatorname{ALP}(\mathrm{U} / \mathrm{L})$ & median (range) & $256(93-2978)$ & $309(208-2943)$ & $251(93-2978)$ & $0.059^{b)}$ \\
\hline $\mathrm{SCr}(\mathrm{mg} / \mathrm{dL})$ & median (range) & $0.68(0.40-7.16)$ & $0.62(0.47-1.49)$ & $0.68(0.40-7.16)$ & $0.850^{b)}$ \\
\hline $\mathrm{WBC}(/ \mu \mathrm{L})$ & median (range) & $5670(2200-21330)$ & $5590(3070-10790)$ & $5700(2200-21330)$ & $0.925^{b)}$ \\
\hline $\mathrm{Hb}(\mathrm{g} / \mathrm{dL})$ & mean \pm S.D. & $11.7 \pm 1.7$ & $11.7 \pm 2.0$ & $11.7 \pm 1.7$ & $0.957^{a)}$ \\
\hline Plt $\left(\times 10^{4} / \mu \mathrm{L}\right)$ & median (range) & $25.0(8.1-61.1)$ & $24.8(15.5-43.9)$ & $25.4(8.1-61.1)$ & $0.991^{b)}$ \\
\hline Neutr $(/ \mu \mathrm{L})$ & median (range) & $3774(790-19624)$ & $3636(1881-8200)$ & $3806(790-19624)$ & $0.981^{b)}$ \\
\hline
\end{tabular}

TP, total protein; S.D., standard deviation; Alb, albumin; T-bil, total bilirubin; AST, aspartate aminotransferase; ALT, alanine aminotransferase; LDH, lactate dehydrogenase; ALP, alkaline phosphatase; SCr, serum creatinine; WBC, white blood cell; Hb, hemoglobin; Plt, platelets; Neutr, neutrophils. $a$ ) Student's $t$-test, $b$ ) Mann-Whitney $U$-test.

Table 3. Comparison of Combinations of Drugs

\begin{tabular}{lcccc}
\hline \hline & & & & \multicolumn{2}{c}{ Eye disorders } \\
\cline { 3 - 4 } & & All patients $(n=128)$ & No $(n=115)$ \\
\hline Ramucirumab & & & $2 / 11(15.4 \%)$ & $9 / 106(7.8 \%)$ \\
Trastuzumab & yes/no & $11 / 117$ & $2 / 11(15.4 \%)$ & $19 / 96(16.5 \%)$ \\
Bevacizumab & yes/no & $21 / 107$ & 1.000 \\
Carboplatin & yes/no & $9 / 119$ & $1 / 12(7.7 \%)$ & $8 / 107(7.0 \%)$ \\
Gemcitabine & yes/no & $29 / 99$ & $2 / 11(15.4 \%)$ & $27 / 88(23.5 \%)$ \\
Dexamethasone (premedication) & yes/no & $13 / 115$ & $2 / 11(15.4 \%)$ & $11 / 104(9.6 \%)$ \\
5-HT antagonists & yes/no & $107 / 21$ & 0.731 \\
Aprepitant & yes/no & $42 / 86$ & $10 / 3(76.9 \%)$ & $97 / 18(84.3 \%)$ \\
NSAIDs & yes/no & $22 / 106$ & $4 / 9(30.8 \%)$ & $38 / 77(33.0 \%)$ \\
Acetaminophen & yes/no & $73 / 55$ & $3 / 10(23.1 \%)$ & $19 / 96(16.5 \%)$ \\
Tramadol or opioids & yes/no & $23 / 105$ & $8 / 5(61.5 \%)$ & $65 / 50(56.5 \%)$ \\
Benzodiazepine receptor agonists & yes/no & $39 / 89$ & $5 / 8(38.5 \%)$ & $18 / 97(15.7 \%)$ \\
Antihistamines & yes/no & $41 / 87$ & 0.697 \\
Steroids & yes/no & $29 / 99$ & $5 / 8(38.5 \%)$ & $34 / 81(29.6 \%)$ \\
Traditional Chinese medicines & yes/no & $24 / 104$ & $6 / 7(46.2 \%)$ & $35 / 80(30.4 \%)$ \\
Pregabalin & yes/no & $61 / 67$ & $3 / 10(23.1 \%)$ & $26 / 89(22.6 \%)$ \\
Proton pump inhibitors & yes/no & $12 / 116$ & $4 / 9(30.8 \%)$ & $20 / 95(17.4 \%)$ \\
Antihypertensives & yes/no & $43 / 85$ & $10 / 3(76.9 \%)$ & $51 / 64(44.3 \%)$ \\
Antidiabetics & yes/no & $44 / 84$ & $1 / 12(7.7 \%)$ & $11 / 104(9.6 \%)$ \\
\hline
\end{tabular}

5-HT, 5-hydroxytryptamine; NSAIDs, non-steroidal anti-inflammatory drugs. a) Fisher's exact probability test.

traditional Chinese medicines concomitantly was significantly higher among those who presented with eye disorders than among those who did not (76.9 vs. $44.3 \%, p=0.038$, Fisher's exact probability test). No significant difference was found for any other factor.

Details of Patients Who Presented with Eye Disorders Caused by PTX or Nab-PTX The details of patients with eye disorders are presented in Table 4. The following symptoms were observed: four patients had conjunctivitis or subconjunctival hemorrhage (3.1\%); three patients had visual acuity reduction $(2.3 \%)$; two patients had blurred vision $(1.6 \%)$; two patients had eye pain $(1.6 \%)$; and one $(0.8 \%)$ patient had eye mucus, blepharitis, stye, watering eyes, photopsia, and muscae volitantes.

With regard to the degree of symptoms, five and eight patients were deemed to have Grade 1 and 2 symptoms, respec- tively. The median number of administrations and cumulative dose at the time of the appearance of symptoms were seven (range, 1-17) and $513 \mathrm{mg} / \mathrm{m}^{2}$ (range, $74.5-1225.9 \mathrm{mg} / \mathrm{m}^{2}$ ). PTX or nab-PTX administration was continued in all cases.

Conjunctivitis, subconjunctival hemorrhage, eye mucus, blepharitis, stye, watering eyes, and photopsia were reversible. The condition of four patients improved following the use of eye drops or eye ointment, whereas that of four others improved spontaneously. However, the cases in which visual acuity reduction, blurred vision, and muscae volitantes were observed were irreversible. Of the three cases in which visual acuity reduction was observed, two subjects continued to experience the symptom without remarkable exacerbation, but in one case, the symptoms were exacerbated. In one of the two cases in which eye pain was observed, the symptoms improved even if nab-PTX administration was continued; 
Table 4. Details of Patients Who Presented with Eye Disorders Caused by PTX or Nab-PTX

\begin{tabular}{|c|c|c|c|c|c|c|}
\hline \multirow{2}{*}{ No. } & \multirow{2}{*}{ Eye disorders } & \multirow{2}{*}{ Grade - } & \multicolumn{2}{|c|}{$\begin{array}{l}\text { At the time of the } \\
\text { appearance of symptoms }\end{array}$} & \multirow{2}{*}{ Clinical course } & \multirow{2}{*}{$\begin{array}{l}\text { Revers- } \\
\text { ible or } \\
\text { irreversible }\end{array}$} \\
\hline & & & $\begin{array}{c}\text { Number of } \\
\text { administrations }\end{array}$ & $\begin{array}{c}\text { Cumulative } \\
\text { dose }\left(\mathrm{mg} / \mathrm{m}^{2}\right)\end{array}$ & & \\
\hline 1 & Eye pain & 1 & 2 & 170.0 & $\begin{array}{l}\text { There was a complaint of eye pain of the right eye. A consultation } \\
\text { with an ophthalmologist resulted in no abnormal findings. Ocular ten- } \\
\text { sion was normal. Visual acuity was } 0.2 \text { for the right eye and } 0.2 \text { for } \\
\text { the left eye. Administration of nab-PTX was continued. Subsequently, } \\
\text { the eye pain improved, but then there was a relapse. }\end{array}$ & Irreversible \\
\hline 2 & $\begin{array}{l}\text { Conjunctivitis } \\
\text { Eye pain }\end{array}$ & 2 & 1 & 177.6 & $\begin{array}{l}\text { There was congestion and a complaint of eye pain. A consultation } \\
\text { with an ophthalmologist resulted in the diagnosis of conjunctivitis with } \\
\text { congestion and mucus in both eyes. The symptoms were improved } \\
\text { with the use of } 0.3 \% \text { gatifloxacin ophthalmic solution and } 0.1 \% \text { fluo- } \\
\text { rometholone ophthalmic suspension. }\end{array}$ & Reversible \\
\hline 3 & $\begin{array}{l}\text { Subconjunctival } \\
\text { hemorrhage }\end{array}$ & 1 & 3 & 288.0 & $\begin{array}{l}\text { There was congestion of the left eye. A consultation with an ophthal- } \\
\text { mologist resulted in the diagnosis of subconjunctival hemorrhage of } \\
\text { the left eye. Subsequently, the symptoms improved spontaneously. }\end{array}$ & Reversible \\
\hline 4 & $\begin{array}{l}\text { Visual acuity reduction } \\
\text { Blurred vision }\end{array}$ & 2 & 7 & 731.1 & $\begin{array}{l}\text { There were complaints of visual acuity reduction and blurred vision. } \\
\text { There was a consultation with an ophthalmologist. Visual acuity was } \\
0.4 \text { for the right eye and } 0.4 \text { for the left eye. Subsequently, nab-PTX } \\
\text { was continued. Although the symptoms continued, no remarkable } \\
\text { exacerbation occurred. }\end{array}$ & Irreversible \\
\hline 5 & $\begin{array}{l}\text { Subconjunctival } \\
\text { hemorrhage }\end{array}$ & 2 & 2 & 513.1 & $\begin{array}{l}\text { There was congestion of the right eye. A consultation with an ophthal- } \\
\text { mologist resulted in the diagnosis of subconjunctival hemorrhage of } \\
\text { the right eye. The symptoms improved with the use of } 0.1 \% \text { pranopro- } \\
\text { fen ophthalmic solution. }\end{array}$ & Reversible \\
\hline 6 & $\begin{array}{l}\text { Eye mucus } \\
\text { Blepharitis }\end{array}$ & 2 & 7 & 627.9 & $\begin{array}{l}\text { There was eye mucus. A consultation with an ophthalmologist resulted } \\
\text { in the diagnosis of blepharitis. The symptoms improved with the use } \\
\text { of } 0.3 \% \text { ofloxacin ophthalmic ointment and } 0.1 \% \text { purified sodium } \\
\text { hyaluronate. }\end{array}$ & Reversible \\
\hline 7 & Stye & 2 & 3 & 287.7 & $\begin{array}{l}\text { There was swelling of right upper eyelid. A consultation with an } \\
\text { ophthalmologist resulted in the diagnosis of a stye. The symptoms } \\
\text { improved with the use of } 1.5 \% \text { levofloxacin ophthalmic solution. }\end{array}$ & Reversible \\
\hline 8 & Visual acuity reduction & 2 & 17 & 1225.9 & $\begin{array}{l}\text { There was a complaint of visual acuity reduction. There was a consul- } \\
\text { tation with an ophthalmologist. Visual acuity was } 0.5 \text { for the right eye } \\
\text { and } 0.8 \text { for the left eye. There were no abnormal findings. PTX was } \\
\text { continued. Although the symptoms continued, there was no remark- } \\
\text { able exacerbation. }\end{array}$ & Irreversible \\
\hline 9 & $\begin{array}{l}\text { Visual acuity reduction } \\
\text { Blurred vision }\end{array}$ & 2 & 7 & 486.0 & $\begin{array}{l}\text { There were complaints of visual acuity reduction and blurred vision. } \\
\text { There was a consultation with an ophthalmologist. Visual acuity was } \\
0.5 \text { for the right eye and } 0.6 \text { for the left eye. PTX was continued. } \\
\text { After } 6 \text { months, visual acuity decreased to } 0.4 \text { for the right eye and } \\
0.4 \text { for the left eye. After further } 2 \text { months, the visual acuity decreased } \\
\text { to } 0.15 \text { for the right eye and } 0.4 \text { for the left eye. PTX was discontin- } \\
\text { ued because of cancer progression. }\end{array}$ & Irreversible \\
\hline 10 & Watering eyes & 1 & 8 & 630.7 & $\begin{array}{l}\text { There was a complaint of watering eyes. A consultation with an oph- } \\
\text { thalmologist revealed no finding of lacrimal duct obstruction. Subse- } \\
\text { quently, the symptoms improved spontaneously. }\end{array}$ & Reversible \\
\hline 11 & $\begin{array}{l}\text { Subconjunctival } \\
\text { hemorrhage }\end{array}$ & 2 & 11 & 902.6 & $\begin{array}{l}\text { There was congestion of the left eye. A consultation with an ophthal- } \\
\text { mologist resulted in the diagnosis of subconjunctival hemorrhage of } \\
\text { the left eye. Subsequently, the symptoms improved spontaneously. }\end{array}$ & Reversible \\
\hline 12 & Photopsia & 1 & 1 & 74.5 & $\begin{array}{l}\text { There was a complaint of photopsia. A consultation with an ophthal- } \\
\text { mologist revealed no abnormal findings. Subsequently, the symptoms } \\
\text { improved spontaneously. }\end{array}$ & Reversible \\
\hline 13 & Muscae volitantes & 1 & 11 & 873.7 & $\begin{array}{l}\text { There was a complaint of discomfort of view. A consultation with an } \\
\text { ophthalmologist resulted in the diagnosis of muscae volitantes. PTX } \\
\text { administration was completed. There was no remarkable exacerbation. }\end{array}$ & Irreversible \\
\hline
\end{tabular}

PTX, paclitaxel; nab-PTX, nanoparticle albumin-bound paclitaxel.

however, there was a relapse afterwards.

Analysis of Risk Factors The univariate analysis of risk factors is shown in Table 5. Factors with $p<0.2$ were a cumulative dose of $\geq 819 \mathrm{mg} / \mathrm{m}^{2}$ ( $\left.p=0.053\right)$, peripheral neuropathy of $\geq$ Grade $2(p=0.027)$, baseline ALT of $\geq 15 \mathrm{U} / \mathrm{L} \quad(p=0.188)$, baseline ALP of $\geq 256 \mathrm{U} / \mathrm{L}(p=0.154)$, concomitant acetaminophen use $(p=0.052)$, and concomitant traditional Chinese medicine use $(p=0.037)$ (Table 5).

The results of the multivariate logistic regression analysis with backward stepwise selection using these six factors are shown in Table 6 . The multivariate logistic regression analysis revealed that a cumulative dose of $\geq 819 \mathrm{mg} / \mathrm{m}^{2}$ (odds ratio: 5.34, 95\% confidence interval: 1.32-21.60, $p=0.019)$ and baseline ALP of $\geq 256 \mathrm{U} / \mathrm{L}$ (odds ratio: $3.74,95 \%$ confidence 
Table 5. Risk Factors Associated with Eye Disorders from Univariate Analyses

\begin{tabular}{|c|c|c|c|}
\hline Variable & $\begin{array}{l}\text { Odds } \\
\text { ratio }\end{array}$ & $\begin{array}{c}95 \% \text { Confidence } \\
\text { interval }\end{array}$ & $\begin{array}{c}p \\
\text { Value }\end{array}$ \\
\hline Age $\geq 65$ years & 1.00 & $0.32-3.15$ & 0.996 \\
\hline Sex: male (versus female) & 0.94 & $0.29-3.04$ & 0.914 \\
\hline $\mathrm{BSA} \geq 1.5 \mathrm{~m}^{2}$ & 2.14 & $0.56-8.21$ & 0.266 \\
\hline ECOG PS $\geq 1$ & 1.17 & $0.36-3.82$ & 0.792 \\
\hline Ocular disease complications & 0.98 & $0.20-4.80$ & 0.980 \\
\hline Previous chemotherapy administration & 0.87 & $0.28-2.75$ & 0.816 \\
\hline PTX (versus nab-PTX) & 0.68 & $0.22-2.16$ & 0.516 \\
\hline Dose intensity $\geq 63 \mathrm{mg} / \mathrm{m}^{2} /$ week & 1.15 & $0.36-3.62$ & 0.816 \\
\hline Cumulative dose $\geq 819 \mathrm{mg} / \mathrm{m}^{2}$ & 3.77 & $0.99-14.40$ & 0.053 \\
\hline Peripheral neuropathy $\geq$ Grade 2 & 3.84 & $1.17-12.60$ & 0.027 \\
\hline \multicolumn{4}{|l|}{ Laboratory data } \\
\hline $\mathrm{TP} \geq 6.8 \mathrm{~g} / \mathrm{dL}$ & 0.53 & $0.17-1.73$ & 0.296 \\
\hline $\mathrm{Alb} \geq 3.8 \mathrm{~g} / \mathrm{dL}$ & 0.84 & $0.27-2.66$ & 0.770 \\
\hline T-bil $\geq 0.5 \mathrm{mg} / \mathrm{dL}$ & 1.50 & $0.44-5.16$ & 0.520 \\
\hline $\mathrm{AST} \geq 20 \mathrm{U} / \mathrm{L}$ & 1.11 & $0.35-3.50$ & 0.862 \\
\hline $\mathrm{ALT} \geq 15 \mathrm{U} / \mathrm{L}$ & 2.29 & $0.67-7.86$ & 0.188 \\
\hline $\mathrm{LDH} \geq 195 \mathrm{U} / \mathrm{L}$ & 0.59 & $0.18-1.92$ & 0.384 \\
\hline $\mathrm{ALP} \geq 256 \mathrm{U} / \mathrm{L}$ & 2.45 & $0.72-8.43$ & 0.154 \\
\hline $\mathrm{SCr} \geq 0.68 \mathrm{mg} / \mathrm{dL}$ & 0.81 & $0.26-2.57$ & 0.725 \\
\hline $\mathrm{WBC} \geq 5670 / \mu \mathrm{L}$ & 0.84 & $0.27-2.66$ & 0.770 \\
\hline $\mathrm{Hb} \geq 11.6 \mathrm{~g} / \mathrm{dL}$ & 1.52 & $0.47-4.92$ & 0.486 \\
\hline Plt $\geq 25.0 \times 10^{4} / \mu \mathrm{L}$ & 0.59 & $0.18-1.92$ & 0.384 \\
\hline Neutr $\geq 3774 / \mu \mathrm{L}$ & 0.84 & $0.27-2.66$ & 0.770 \\
\hline \multicolumn{4}{|l|}{ Combinations of drugs } \\
\hline Ramucirumab & 2.14 & $0.41-11.20$ & 0.367 \\
\hline Trastuzumab & 0.92 & $0.19-4.48$ & 0.916 \\
\hline Bevacizumab & 1.11 & $0.13-9.69$ & 0.922 \\
\hline Carboplatin & 0.59 & $0.12-2.84$ & 0.513 \\
\hline Gemcitabine & 1.72 & $0.34-8.77$ & 0.515 \\
\hline Dexamethasone (premedication) & 0.62 & $0.16-2.47$ & 0.497 \\
\hline $5-\mathrm{HT}_{3}$ antagonists & 0.90 & $0.26-3.11$ & 0.869 \\
\hline Aprepitant & 1.52 & $0.38-6.03$ & 0.555 \\
\hline NSAIDs & 1.23 & $0.38-3.99$ & 0.729 \\
\hline Acetaminophen & 3.37 & $0.99-11.50$ & 0.052 \\
\hline Tramadol or opioids & 1.49 & $0.45-4.88$ & 0.511 \\
\hline Benzodiazepine receptor agonists & 1.96 & $0.61-6.25$ & 0.256 \\
\hline Antihistamines & 1.03 & $0.26-4.01$ & 0.970 \\
\hline Steroids & 2.11 & $0.59-7.54$ & 0.250 \\
\hline Traditional Chinese medicines & 4.18 & $1.09-16.00$ & 0.037 \\
\hline Pregabalin & 0.79 & $0.09-6.65$ & 0.827 \\
\hline Proton pump inhibitors & 0.87 & $0.25-2.99$ & 0.820 \\
\hline Antihypertensives & 1.22 & $0.37-3.97$ & 0.744 \\
\hline Antidiabetics & 0.42 & $0.05-3.43$ & 0.419 \\
\hline
\end{tabular}

BSA, body surface area; ECOG, Eastern Cooperative Oncology Group; PS, performance status; PTX, paclitaxel; nab-PTX, nanoparticle albumin-bound paclitaxel; $\mathrm{TP}$, total protein; Alb, albumin; T-bil, total bilirubin; AST, aspartate aminotransferase; ALT, alanine aminotransferase; LDH, lactate dehydrogenase; ALP, alkaline phosphatase; SCr, serum creatinine; WBC, white blood cell; Hb, hemoglobin; Plt platelets; Neutr, neutrophils; 5-HT, 5-hydroxytryptamine; NSAIDs, non-steroidal antiinflammatory drugs.

Table 6. Risk Factors Associated with Eye Disorders from Multivariate Analyses

\begin{tabular}{cccc}
\hline \hline Variable & Odds ratio & $\begin{array}{c}95 \% \text { Confidence } \\
\text { interval }\end{array}$ & $p$ Value \\
\hline Cumulative dose $\geq 819 \mathrm{mg} / \mathrm{m}^{2}$ & 5.34 & $1.32-21.60$ & 0.019 \\
$\mathrm{ALP} \geq 256 \mathrm{U} / \mathrm{L}$ & 3.74 & $1.02-13.70$ & 0.046 \\
\hline
\end{tabular}

ALP, alkaline phosphatase. interval: $1.02-13.70, p=0.046)$ were significant risk factors associated with eye disorders (Table 6). The likelihood ratio test result was significant $(p<0.05)$ and multicollinearity was not observed.

\section{DISCUSSION}

Of 128 subjects, $13(10.2 \%)$ had eye disorders with Grade 1 or Grade 2 symptoms. The symptoms involving the anterior segment of eyeball, such as conjunctivitis and subconjunctival hemorrhage, improved with the use of eye drops or eye ointment and were reversible. However, the cases of visual acuity reduction, blurred vision, or muscae volitantes were irreversible (Table 4). The multivariate logistic regression analysis revealed that a higher cumulative dose $\left(\geq 819 \mathrm{mg} / \mathrm{m}^{2}\right)$ and a higher baseline ALP ( $\geq 256 \mathrm{U} / \mathrm{L}$ ) were risk factors significantly associated with eye disorders (Table 6).

In this study, eye disorders were observed in $10.2 \%$ of patients. Generally, eye disorders are considered rare, but the occurrence was relatively frequent in this study. This was considered to result from the pharmacist taking sufficient time in the patient interview and monitoring adverse events. However, these conditions were diagnosed by an ophthalmologist and defined as eye disorders and it is therefore unlikely that the pharmacists have overestimated the incidence of eye disorders.

Several reports of optic nerve disturbance caused by PTX were reported in the 1990 s. $^{9-11)}$ In 2006, Scaioli et al. reported that the most likely mechanism of the visual symptoms and electrophysiological changes caused by PTX use was vascular dysregulation in the retina or ischemic mechanisms involving the optic nerve. ${ }^{12)}$ Cystoid macular edema, which has recently been reported as a problem, was reported for the first time following PTX use in 20074) and nab-PTX use in 2008. ${ }^{15}$ ) Since then, there have been frequent reports of cystoid macular edema following the use of PTX ${ }^{18-25)}$ and nab-PTX. ${ }^{26-32)}$ The mechanism is related to a theory that includes toxicity to Müller cells, subsequent intracellular fluid accumulation, and the subclinical leakage of extracellular fluid. ${ }^{14)}$ Moreover, it is theorized that it is likely to originate from dysfunction of the retinal pigment epithelium caused by effects on microtubule functions. ${ }^{16)}$ However, although the complete picture has not yet been clarified, it is clear that PTX and nab-PTX are distributed in the optic nerve and the eyeball, ${ }^{34)}$ and it is almost certain that some kind of action occurs there. In this study, no cases of cystoid macular edema were noted. However, irreversible symptoms, such as visual acuity reduction, blurred vision, and muscae volitantes, were observed (Table 4). Although all cases were relatively mild, attention to visual acuity and the visual field is therefore necessary during the administration of PTX or nab-PTX.

In contrast, symptoms of the anterior segment of the eyeball, such as conjunctivitis and subconjunctival hemorrhage, improved after the use of eye drops or eye ointment and were reversible (Table 4). It was reported that the intravenous administration of docetaxel, a taxane similar to PTX, led to distribution into the tear fluid. ${ }^{35)}$ A similar phenomenon occurs in PTX or nab-PTX, indicating the possibility that the ocular mucosa was impaired directly by the drug. In addition, eyelashes may be lost because of PTX or nab-PTX use; hence, it is possible that damage to the ocular mucosa may have been due to some extraneous factors. 
The multivariate logistic regression analysis revealed that a higher cumulative dose was a significant risk factor associated with eye disorders (Table 6). It was reported that the cumulative dose of docetaxel was significantly higher in patients with canalicular stenosis. ${ }^{36)}$ We also reported that the dose intensity was significantly higher in patients with docetaxel-induced epiphora. ${ }^{7)}$ Therefore, with the use of taxanes such as PTX and docetaxel, a higher dose may increase the risk of eye disorders.

The proportion of patients who used traditional Chinese medicines concomitantly was significantly higher among those who presented with eye disorders than among those who did not (Table 3). Of 128 subjects, 61 (47.7\%) used traditional Chinese medicines concomitantly (Table 3 ). The most frequently used was Goshajinkigan, which was used by for $86.9 \%(53 / 61)$ of these patients. This was thought to have been used to relieve peripheral neuropathy induced by PTX or nab-PTX. In this study, the proportion of patients with peripheral neuropathy of $\geq$ Grade 2 was significantly higher among those who presented with eye disorders than among those who did not (Table 1). Therefore, it was presumed that the proportion of patients that used Goshajinkigan to relieve peripheral neuropathy was also high. In general, peripheral neuropathy induced by PTX or nab-PTX causes symptom exacerbation in a dose-dependent manner. The cumulative dose was also significantly higher in those who presented with eye disorders than in those who did not (Table 1). The concomitant use of traditional Chinese medicine, peripheral neuropathy of $\geq$ Grade 2 , and the cumulative dose were significant factors in the univariate analyses $(p<0.2)$ (Table 5). However, the concomitant use of traditional Chinese medicine and peripheral neuropathy of $\geq$ Grade 2 were not significant factors in the multivariate analyses (Table 6); this was because the cumulative dose was the strongest factor and suppressed the effect of the other two factors.

The multivariate logistic regression analysis revealed that higher baseline ALP ( $\geq 256 \mathrm{U} / \mathrm{L})$ was a significant risk factor associated with eye disorders (Table 6). Although there was no statistically significant differences, AST and ALT, which are representative parameters of liver function, were also higher in those who presented with eye disorders than in those who did not (Table 2). PTX is metabolized in the liver. ${ }^{34)}$ It is possible that metabolic ability decreases owing to the deterioration of the liver function and the proportion of the drug distributed to the eyeball may increase. However, it was difficult to demonstrate this point in our study; therefore, it should be investigated in future studies.

All eye disorders noted in this study were Grade 1 or Grade 2 ; however, as they were self-reported symptoms, it is undeniable that they exerted an impact on the patient's QOL. Even with a relatively rare adverse event, such as an eye disorder, it is important that pharmacists are proactive with regard to selfreported symptoms to ensure the safety of patients undergoing cancer chemotherapy.

This was a retrospective study with a limited number of cases from a single facility. Therefore, there are limitations to the generalization of the results. However, this report could be valuable for future discussion of eye disorders caused by PTX and nab-PTX.

In conclusion, it was determined that PTX- and nab-PTXrelated eye disorders might be influenced by the cumulative dose and baseline ALP.
Acknowledgments We would like to thank all the members of the staff of the Department of Pharmacy, Kyoto Okamoto Memorial Hospital.

Conflict of Interest The authors declare no conflict of interest.

\section{REFERENCES}

1) Kashiwagi H. Ocular disorders of anticancer drugs-ocular side effects. Gan To Kagaku Ryoho, 37, 1639-1644 (2010).

2) Mansur C, Pfeiffer ML, Esmaeli B. Evaluation and management of chemotherapy-induced epiphora, punctal and canalicular stenosis, and nasolacrimal duct obstruction. Ophthal. Plast. Reconstr. Surg., 33, 9-12 (2017)

3) Noguchi Y, Kawahara Y, Omori K, Matsumoto K, Minegaki T, Tsujimoto M, Nishiguchi K, Tokuyama Y. Introduction and evaluation of all adverse effect reporting service provided by pharmacists stationed in the outpatient cancer chemotherapy room. J. Jpn. Soc. Hosp. Pharm., 46, 1273-1277 (2010).

4) Noguchi $Y$, Nishimura R, Kawara H, Omori K, Matsumoto K, Tokuyama Y, Uchiyama K, Shimizu Y. Survey of current status of adverse ocular reactions to paclitaxel and a retrospective analysis for aiding in early detection of adverse reactions. Gan To Kagaku Ryoho, 40, 819-822 (2013).

5) Noguchi Y, Mitani T, Kawara H, Tokuyama Y, Tamura Y, Uchiyama K, Shimizu Y. A case of lacrimal duct obstruction caused by capecitabine. Gan To Kagaku Ryoho, 42, 123-125 (2015).

6) Noguchi Y, Kawashima Y, Kawara H, Tokuyama Y, Tamura Y, Uchiyama K, Shimizu Y. A retrospective analysis of eye disorders due to oxaliplatin. Gan To Kagaku Ryoho, 42, 1401-1405 (2015).

7) Noguchi Y, Kawashima Y, Kawara H, Tokuyama Y, Tamura Y, Uchiyama K, Shimizu Y. A retrospective analysis of epiphora due to docetaxel. Gan To Kagaku Ryoho, 43, 737-741 (2016).

8) Noguchi Y, Kawashima Y, Kawara H, Kaneko M, Nakauchi H, Tokuyama Y. An undeniable case of optic neuropathy due to cabazitaxel. Gan To Kagaku Ryoho, 43, 777-779 (2016).

9) Capri G, Munzone E, Tarenzi E, Fulfaro F, Gianni L, Caraceni A, Martini C, Scaioli V. Optic nerve disturbances: a new form of paclitaxel neurotoxicity. J. Natl. Cancer Inst., 86, 1099-1101 (1994).

10) Seidman AD, Barrett S, Canezo S. Photopsia during 3-hour paclitaxel administration at doses $\geq 250 \mathrm{mg} / \mathrm{m}^{2}$. J. Clin. Oncol., 12, 1741-1742 (1994).

11) Hofstra LS, de Vries EG, Willemse PH. Ophthalmic toxicity following paclitaxel infusion. Ann. Oncol., 8, 1053 (1997).

12) Scaioli V, Caraceni A, Martini C, Curzi S, Capri G, Luca G. Electrophysiological evaluation of visual pathways in paclitaxel-treated patients. J. Neurooncol., 77, 79-87 (2006).

13) McCartney E, Valluri S, Rushing D, Burgett R. Upper and lower system nasolacrimal duct stenosis secondary to paclitaxel. Ophthal. Plast. Reconstr. Surg., 23, 170-171 (2007).

14) Joshi MM, Garretson BR. Paclitaxel maculopathy. Arch. Ophthalmol., 125, 709-710 (2007).

15) Smith SV, Benz MS, Brown DM. Cystoid macular edema secondary to albumin-bound paclitaxel therapy. Arch. Ophthalmol., 126, 1605-1606 (2008).

16) Kuznetcova TI, Cech P, Herbort CP. The mystery of angiographically silent macular oedema due to taxanes. Int. Ophthalmol., 32, 299-304 (2012).

17) Lee HS, Ha JY, Choi W, Yoon KC. Bilateral corneal epithelial lesions associated with paclitaxel. Optom. Vis. Sci., 93, 1333-1336 (2016).

18) Georgakopoulos CD, Makri OE, Vasilakis P, Exarchou A. Angiographically silent cystoid macular oedema secondary to paclitaxel therapy. Clin. Exp. Optom., 95, 233-236 (2012).

19) Ham DS, Lee JE, Kim HW, Yun IH. A case of cystoid macular 
edema associated with paclitaxel chemotherapy. Korean J. Ophthalmol., 26, 388-390 (2012).

20) Koo NK, Kim YC. A case of paclitaxel-induced maculopathy treated with methazolamide. Korean J. Ophthalmol., 26, 394-397 (2012).

21) Modi D, Dubovy SR. Non-leaking cystoid maculopathy secondary to systemic paclitaxel. Ophthalmic Surg. Lasers Imaging Retina, 44, 183-186 (2013).

22) Freitas-da-Costa P, Brandão E, Bragança T, Falcão-Reis F, Carneiro A. Multimodal imaging in paclitaxel-induced macular edema: the microtubule disfunction. Cutan. Ocul. Toxicol., 34, 347-349 (2015).

23) Tezcan Y, Surmeli M, Tastekin D, Koc M. Bilateral cystoid macular edema secondary to paclitaxel treatment. Arch. Iran Med., 18, 606-607 (2015).

24) Nakao S, Ikeda Y, Emi Y, Ishibashi T. Possibility of Müller cell dysfunction as the pathogenesis of paclitaxel maculopathy. Ophthalmic Surg. Lasers Imaging Retina, 47, 81-84 (2016).

25) Dwivedi R, Tiroumal S. Possible efficacy of topical dorzolamide in the treatment of paclitaxel-related cystoid macular edema. Retin. Cases Brief Rep., 12, 75-79 (2018).

26) Murphy CG, Walsh JB, Hudis CA, Lake D, Theodoulou M. Cystoid macular edema secondary to nab-paclitaxel therapy. J. Clin. Oncol., 28, e684-e687 (2010).

27) Rahimy E, Sarraf D. Cystoid macular edema secondary to nanoparticle albumin-bound paclitaxel therapy. Ophthalmic Surg. Lasers Imaging Retina, 44, 187-189 (2013).

28) Rahman HT, Yeh S, Bergstrom CS. Cystoid macular edema without leakage secondary to nab-paclitaxel (Abraxane): clinical experience with intravitreal bevacizumab. J. Ocul. Pharmacol. Ther., 29,
360-362 (2013)

29) Matsuoka N, Hasebe H, Mayama T, Fukuchi T. Sub-tenon injections of triamcinolone acetonide had limited effect on cystoid macular edema secondary to nanoparticle albumin-bound-paclitaxel (Abraxane). Case Rep. Ophthalmol. Med., 2015, 181269 (2015).

30) Tanaka Y, Bando H, Hara H, Ito Y, Okamoto Y. Cystoid macular edema induced by nab-paclitaxel. Breast Cancer, 22, 324-326 (2015).

31) Hassall MM, Andrew NH. Single-eye trial of a topical carbonic anhydrase inhibitor versus intravitreal bevacizumab for the treatment of taxane drug-induced cystoid macula oedema. BMJ Case Rep., doi: 10.1136/bcr-2015-212733 (2016).

32) Park E, Goldberg NR, Adams S. Nab-paclitaxel-induced cystoid macular edema in a patient with pre-existing optic neuropathy. Anticancer Drugs, 27, 580-584 (2016).

33) Kanda Y. Investigation of the freely available easy-to-use software 'EZR' for medical statistics. Bone Marrow Transplant., 48, 452-458 (2013)

34) TAXOL Japanese interview form.

35) Esmaeli B, Ahmadi MA, Rivera E, Valero V, Hutto T, Jackson DM, Newman RA. Docetaxel secretion in tears: association with lacrimal drainage obstruction. Arch. Ophthalmol., 120, 1180-1182 (2002)

36) Esmaeli B, Hortobagyi GN, Esteva FJ, Booser D, Ahmadi MA, Rivera E, Arbuckle R, Delpassand E, Guerra L, Valero V. Canalicular stenosis secondary to weekly versus every-3-weeks docetaxel in patients with metastatic breast cancer. Ophthalmology, 109, 1188-1191 (2002). 